\title{
Novel highly sensitive and reversible electrospun nanofibrous chemosensor-filters composed of poly (HEMA-co-MNA) and bpy-F-bpy with metal-ion- modulated multicolor fluorescence emission
}

\author{
Chih-Chien Hung ${ }^{1}$, Chi-Ching Kuo ${ }^{1}$, Nian-Kuan Weng ${ }^{2}$, Wen-Chung Wu${ }^{2}$, Bo-Yu Chen ${ }^{1}$, Chia-Jung Cho ${ }^{1}$, \\ I-Jui Hsu ${ }^{1}$, Yu-Cheng $\mathrm{Chiu}^{3}$ and Wen-Chang Chen ${ }^{3}$
}

Novel multifunctional fluorescent electrospun (ES) nanofibers exhibiting high sensitivity for various metal ions were prepared from binary blends of poly(2-hydroxyethyl methacrylate-co- $\mathrm{N}$-methylolacrylamide) (poly(HEMA-co-NMA)) and 9,9-dihexylfluorene2,7-bipyridine (bpy-F-bpy) by using a single-capillary spinneret. Different compositions of poly(HEMA-co-NMA) were synthesized through free-radical polymerization. The HEMA moieties were designed to exhibit hydrophilic properties, and the NMA content substantially affected the stability of the ES nanofibers in water. Experimental optical spectra and simulation results demonstrated that the fluorescent sensing probe bpy-polyfluorene-bpy could detect various metal ions. ES nanofibers prepared from copolymers with a 77:23 HEMA:NMA ratio blended with 5\% bpy-F-bpy (P2-5) exhibited apparent color change from blue to green, color change from blue to blue-green and fluorescence quenching when detecting $\mathrm{Zn}^{2+}, \mathrm{Hg}^{2+}$ and $\mathrm{Cu}^{2+}$, respectively. The P2-5 ES nanofibers exhibited ultrasensitivity for $\mathrm{Zn}^{2+}\left(10^{-7}-10^{-3} \mathrm{M}\right)$ because of the $70 \mathrm{~nm}$ red shift of the emission maximum, and high reversibility because of their on-off switchable fluorescence emission upon the sequential addition of $\mathrm{Zn}^{2+}$ and ethylenediaminetetraacetic acid cycled several times. These results and a microfluidics system study indicated that the nanofibers, which have a high surface-to-volume ratio, can be used as 'naked eye' sensors for sensing various metal ions and as efficient multifunctional chemosensor-filtering devices.

Polymer Journal (2016) 48, 439-449; doi:10.1038/pj.2015.127; published online 20 January 2016

\section{INTRODUCTION}

Chromogenic and fluorogenic signaling probes co.mposed of chelating ligands for detecting metal ions have attracted extensive scientific interest in biological and environmental sensory device applications because their photophysical properties can be tuned markedly by detecting various metal ions such as $\mathrm{Zn}^{2+}, \mathrm{Hg}^{2+}, \mathrm{Cu}^{2+}$ and $\mathrm{Fe}^{2+}$. Various chemosensors based on small molecules, ${ }^{1-9}$ nanomaterials, ${ }^{10-15}$ and polymers or conjugated copolymers ${ }^{16-21}$ have been reported. Conjugated copolymers, namely polyfluorene- and poly (phenylenevinylene)-type copolymers containing metal ion binding sites, such as 1,10-phenanthroline and 2,2'-bipyridine (bpy), exhibited a strong ionochromic effect. These copolymers can be applied in metal ion sensors because they exhibit sensitive, selective and highly reversible ion-responsive performance. ${ }^{22-25}$ Wang and Wasielewski ${ }^{22}$ reported that the fluorescence emission band of bpy-poly(phenylenevinylene)-based polymers upon exposure to pollutant metal ions includes $\mathrm{Zn}^{2+}, \mathrm{Cd}^{2+}$ and $\mathrm{Hg}^{2+}$ and could be red-shifted by up to $120 \mathrm{~nm}$ because of ion-recognition-induced conjugation enhancement and electronic density changes on the main chains of the polymers. $\mathrm{Ma}$ and colleagues reported that, by adjusting the bpy content in the backbone of bpy-polyfluorene-based copolymers, the emission color of a polymer solution could be tuned from blue to green when it interacted with $\mathrm{Zn}^{2+}$, suggesting that the resultant emission colors depend on the number of chelating units in the copolymer backbone. ${ }^{25}$ However, most of the mentioned studies focused on the solution, thin film and bulk solid states. ${ }^{1-25}$ The morphology and photophysical properties for sensing the metal ions of polyfluorenetype conjugated copolymers containing bpy-based electrospun (ES) nanofibers have yet to be explored.

Electrospinning is a simple, versatile, low-cost technique for assembling various functional nanofibers that enables flexible and nanoscaled morphology tuning and high-throughput continuous production. ${ }^{26-33}$ The high surface-to-volume ratio of ES nanofibers has motivated extensive studies on sensory applications such as $\mathrm{pH}$, temperature and volatile gas sensing. ${ }^{34-40}$ However, few studies have reported fluorescent ES nanofibrous membranes for use in

\footnotetext{
${ }^{1}$ Institute of Organic and Polymeric Materials, National Taipei University of Technology, Taipei, Taiwan; ${ }^{2}$ Department of Chemical Engineering, National Cheng Kung University, Tainan, Taiwan and ${ }^{3}$ Department of Chemical Engineering, National Taiwan University, Taipei, Taiwan

Correspondence: Professor C-C Kuo or Professor I-J Hsu or Professor W-C Chen, Institute of Organic and Polymeric Materials, National Taipei University of Technology, No 1, Sec 3, Chung-hsiao E. Road, Taipei 10608, Taiwan.

E-mail: kuocc@mail.ntut.edu.tw or ijuihsu@ntut.edu.tw or chenwc@ntu.edu.tw

Received 29 October 2015; revised 29 November 2015; accepted 29 November 2015; published online 20 January 2016
} 


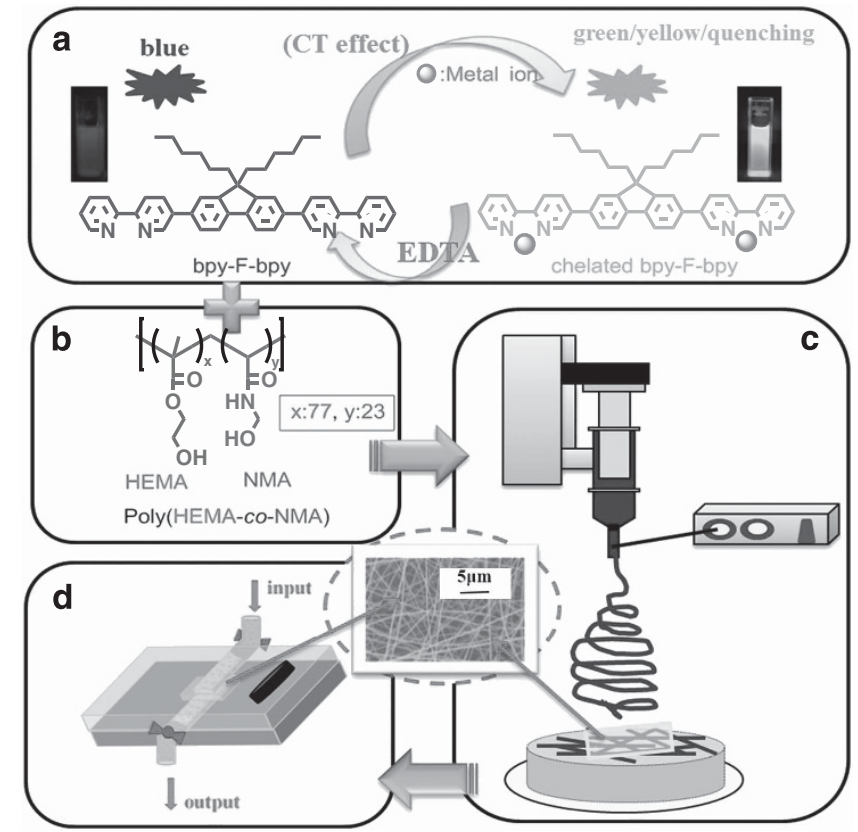

Figure 1 Design of multifunctional sensory ES nanofibers from poly(HEMAco-NMA)/bpy-F-bpy blends with fluorescence emission in various colors for sensing different metal ions. (a) Variation of fluorescence emission colors of the bpy-F-bpy probe during a metal ion and EDTA cycle. (b) Polymerization and chemical structure of poly(HEMA-co-NMA). (c) Fabrication of ES nanofibers from the blends. (d) Microfluidics system for real-time metal ion sensing by the ES nanofiber membrane. bpy-F-bpy, 9,9-dihexylfluorene-2,7bipyridine; EDTA, ethylenediaminetetraacetic acid; ES, electrospun; HEMA, 2-hydroxyethyl methacrylate; NMA, $\mathrm{N}$-methylolacrylamide. A full color version of this figure is available at Polymer Journal online.

metal-ion-sensitive optical sensors and water purification filters. ${ }^{41-44}$ Samuelson and colleagues reported highly responsive fluorescence-quenching-based optical sensors for $\mathrm{Fe}^{3+}$ and $\mathrm{Hg}^{2+}$ that were prepared from poly(acrylic acid)-poly(pyrene menthanol) ES nanofibrous membranes. ${ }^{41}$ Wang and colleagues demonstrated that a novel napthalimide-functionalized nanofibrous film prepared through copolymerization and electrospinning exhibited high sensitivity on $48 \mathrm{~nm}$ blue-shifted emission in fluorescence spectra when detecting $\mathrm{Cu}^{2+}$ in an aqueous solution. ${ }^{42}$ Recently, Meng and our research group developed a real-time $\mathrm{Zn}^{2+}$ sensor with high sensitivity and cell medium compatibility by using ES nanofibers, which were prepared from blends of a fluorescent probe molecule for sensing $\mathrm{Zn}^{2+}$ and a hydrogel polymer, poly(2-hydroxyethyl methacrylate)(poly HEMA). ${ }^{45}$ Metal-ion-sensitive probes composed of bipyridine-containing fluorene (bpy-F) exhibited various fluorescence emission characteristics including color changing and quenching when they interacted with different metal ions because of the high sensitivity of fluorene to external structural perturbations and electron density changes within the fluorene backbone. Therefore, combining the superhydrophilic property of poly HEMA, the bpy-F metal-ion-tunable luminescence of sensing and chelating pollutant metal ions, and the high surface-to-volume ratio and nonwoven structure of ES nanofibers would create a new type of material for application in simultaneous metal ion sensing and water purification. In addition, it is of value to explore the effect of various metal ions on the emission of bpy-F-based ES nanofiber membranes as well as their sensing efficiency in a real-time detecting system.

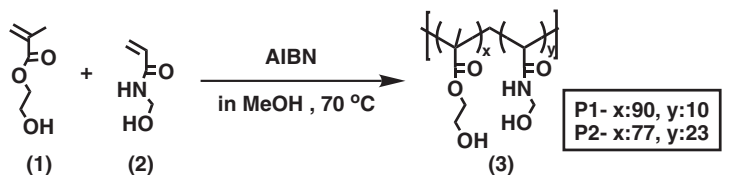

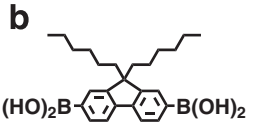

(4)

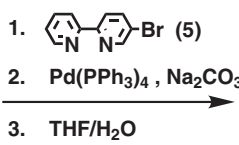

3. $\mathrm{THF} / \mathrm{H}_{2} \mathrm{O}$

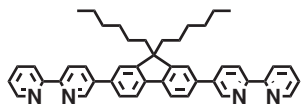

(6)
Scheme 1 Synthesis of (a) poly(HEMA-co-NMA) random copolymers and (b) bpy-F-bpy.

In this study, we developed ES nanofibrous membranes consisting of copolymers containing a hydrophilic hydrogel material (HEMA) and chemical cross-linkable segment, $N$-methylolacrylamide (NMA), blended with a metal-ion-chelating probe, 9,9-dihexylfluorene-2, 7-bipyridine (bpy-F-bpy). These membranes can be used as both sensors and filters. Figure 1 illustrates the fabrication process. We combined synthesis, electrospinning, optical sensor application and morphological characteristics to realize these membranes. As shown in Scheme 1, random copolymers of poly(HEMA-co-NMA) were synthesized through free-radical copolymerization, and bpy-F-bpy was synthesized. Photoluminescence (PL) and UV-visible (UV-vis) spectra obtained through experiments and simulations of a bpy-polyfluorene-bpy solution in which the membranes were used in detecting various metal ions were compared. ES nanofibers composed of poly(HEMA-co-NMA) blended with 1, 3 or $5 \%$ bpy-Fbpy were fabricated using a single-capillary spinneret and then posttreated to enhance their stability in water through chemical cross-linking. The nanofiber morphologies were studied using a field-emission scanning electron microscope (FE-SEM) and laser confocal microscope. The fluorescence emission transitions of the response of various metal ions in the PL and UV-vis spectra were studied. The experimental results suggest that the ES nanofibrous membranes have high reversibility and real-time metal ion detection ability; thus, they exhibit potential for application in simultaneous environmental sensing and water purification.

\section{EXPERIMENTAL PROCEDURE}

\section{Materials}

2-Hydroxyethyl methacrylate, HEMA (97\%, Aldrich Chemical, St Louis, MO, USA) was passed through an $\mathrm{Al}_{2} \mathrm{O}_{3}$ column before polymerization. $\mathrm{N}$ methylolacrylamide (NMA) was provided by Tokyo Chemical Industry, Tokyo, Japan. 2,2'-Azobis(2-methylpropionitrile) (AIBN, Acros, 99\%) was recrystallized from an ethanol solution. 5-Bromo-2,2"-bipyridine was prepared from 2bromopyridine and 2,5-dibromopyridine through the Stille coupling reaction, according to the literature. ${ }^{46}$ (9,9-Dihexyl-9H-fluorene- 2,7-diyl)diboronic acid, sodium carbonate and tetrakis(triphenylphosphine) palladium(0) were purchased from Aldrich Chemical and used without purification. Methanol $(\mathrm{MeOH})$ and tetrahydrofuran (THF) were dried and distilled under $\mathrm{N}_{2}$. The perchlorate salts of all metal ions were purchased from Aldrich Chemical. Ethylenediaminetetraacetic acid tetrasodium salt hydrate (EDTA, 98\%) was purchased from Alfa Aesar (Ward Hill, MA, USA).

\section{Synthesis of poly(HEMA-co-NMA) copolymer}

Poly(HEMA-co-NMA) was synthesized through free-radical copolymerization of the monomers HEMA and NMA, as illustrated in Scheme 1. Poly(HEMAco-NMA) copolymers with different monomer ratios were denoted P1 and P2, as listed in Table 1. The concentration of AIBN used as the initiator was 0.007 м. A reaction mixture containing $\mathrm{MeOH}$ and three monomers was degassed by bubbling nitrogen for $30 \mathrm{~min}$ and then reacted at $70{ }^{\circ} \mathrm{C}$ for $24 \mathrm{~h}$. 
Table 1 Results of poly(HEMA-co-PNMA) synthesis under various conditions

\begin{tabular}{lcccc}
\hline Polymer & Composition ${ }^{\mathrm{a}}$ (HEMA:NMA) & $\mathrm{M}_{n}^{\mathrm{b}}\left(\mathrm{g} \mathrm{mol}^{-1}\right)$ & $P \mathrm{ll}^{\mathrm{b}}$ & $\eta^{\mathrm{c}}\left(\mathrm{kg}(\mathrm{m} \cdot \mathrm{s})^{-1}\right)$ \\
\hline P1 & $90: 10$ & 52830 & 2.66 & $1.4 \times 10^{-3}$ \\
P2 & $77: 23$ & 60290 & 2.82 & $6.6 \times 10^{-3}$ \\
\hline
\end{tabular}

Abbreviations: HEMA, 2-hydroxyethyl methacrylate; $M_{\mathrm{n}}$, number-averaged molecular weight;

NMA, $N$-methylolacrylamide; PDI, polydispersity index.
aMolar ratio (\%), estimated from ${ }^{1} \mathrm{H}$ NMR.

aolar ratio (\%), estimated from ${ }^{1} \mathrm{H}$ NMR.

Determined by gel permeation chromatography with $N, N$-dimethylformamide eluent.

'The viscosities of the polymer solutions (10 wt\% in $\mathrm{MeOH})$.

The reaction mixture was poured into ether, precipitated, filtered and finally dried at $30-35^{\circ} \mathrm{C}$ under vacuum to obtain the two polymers. Table 1 lists the number-averaged molecular weight and polydispersity index estimated through gel permeation chromatography (GPC) of both P1 and P2.

\section{Synthesis of P1}

A reaction mixture of $5000 \mathrm{mg}$ ( $38.42 \mathrm{mmol})$ of HEMA, $388 \mathrm{mg}(3.84 \mathrm{mmol})$ of NMA, $8.7 \mathrm{mg}(0.053 \mathrm{mmol})$ of AIBN and $22 \mathrm{ml}$ of methanol was used to afford a white solid (3.5 g, yield: $64.9 \%)$. Number-averaged molecular weight and polydispersity index estimated from GPC are 52830 and 2.66, respectively. ${ }^{1} \mathrm{H}$ NMR (d-dimethyl sulfoxide, $300 \mathrm{MHz}$ ): $\delta$ (p.p.m.) $=0.78-1.92$ (peak a, b, c), 3.50-3.62 (peak e), 3.76-3.90 (peak d), 4.50-4.62 (peak g), 4.84-5.16 (peak f), 5.36-5.52 (peak h).

\section{Synthesis of P2}

A reaction mixture of $4000 \mathrm{mg}$ ( $30.74 \mathrm{mmol})$ of HEMA, $932 \mathrm{mg}(9.22 \mathrm{mmol})$ of NMA, $8.7 \mathrm{mg}(0.053 \mathrm{mmol})$ of AIBN and $20 \mathrm{ml}$ of methanol was used to afford a white solid. (2.9 g, yield: $58.7 \%$ ) Number-averaged molecular weight and polydispersity index estimated from GPC are 60290 and 2.82, respectively. ${ }^{1} \mathrm{H}$ NMR (d-dimethyl sulfoxide, $300 \mathrm{MHz}$ ): $\delta$ (p.p.m.) $=0.78-1.92$ (peak a, b, c), 3.50-3.62 (peak e), 3.76-3.90 (peak d), 4.50-4.62 (peak g), 4.84-5.16 (peak f), 5.36-5.52 (peak h).

\section{Synthesis of bpy-F-bpy}

Bpy-F-Bpy probe was synthesized by the Suzuki coupling reaction between 9,9-dihexylfluorene-2,7-diboronic acid (4) and 5-bromo-2,2-bipyridine (5). Typically, $4(0.45 \mathrm{~g}, 1.07 \mathrm{mmol}), 5(0.5 \mathrm{~g}, 2.13 \mathrm{mmol})$ and $\mathrm{Pd}\left(\mathrm{PPh}_{3}\right)_{4}$ $(0.036 \mathrm{~g}, 0.03 \mathrm{mmol})$ were dissolved in THF $(10 \mathrm{ml})$ under nitrogen atmosphere. Then, $\mathrm{Na}_{2} \mathrm{CO}_{3}(\mathrm{aq})\left(0.44 \mathrm{~g}, 2 \mathrm{M}\right.$ in $\left.\mathrm{H}_{2} \mathrm{O}\right)$ was added, and the flask was immersed in a preheated oil bath at $70^{\circ} \mathrm{C}$ overnight. The reaction was quenched by exposure to air, extracted with $\mathrm{EA} / \mathrm{H}_{2} \mathrm{O}(100 \mathrm{ml} / 50 \mathrm{ml}, \mathrm{v} / \mathrm{v})$ and the Pd complex was removed through a Kieselguhr column. The crude product was separated from the crude reaction mixture by chromatography and further purified by precipitation from hexane. The slightly yellow solids of 9,9-dihexylfluorene-2,7-bipyridine (6) was obtained (0.264 g, 38\%). ${ }^{1} \mathrm{H}$ NMR $\left(\mathrm{CDCl}_{3}, 300 \mathrm{MHz}\right): \delta$ (p.p.m.) $=0.78-1.20$ p.p.m. $\left(11 \mathrm{H}, \mathrm{Ar}-\left(\mathrm{CH}_{2}\left(\mathrm{CH}_{2}\right)_{4} \mathrm{CH}_{3}\right)\right.$ 2), 2.08-2.1 (2H, Ar- $\left.\left(\mathrm{CH}_{2}\left(\mathrm{CH}_{2}\right)_{4} \mathrm{CH}_{3}\right)_{2}\right), 7.26-9.0(10 \mathrm{H}$, pyridine and fluorine aromatic protons).

\section{Fabrication of cross-linked ES nanofibers}

Poly(HEMA-co-NMA) (200 $\mathrm{mg} \mathrm{ml}^{-1}$; P1 and P2) and P1 and P2 blended with 1,3 or $5 \mathrm{wt} \%$ (with respect to the polymer) of the bpy-F-bpy probe were dissolved in $\mathrm{MeOH}$ to prepare the ES nanofibers. A single-capillary spinneret electrospinning device was used to produce the ES nanofibers, as described in our previous reports. ${ }^{28,30,37,39}$ The polymer solution was fed into a metallic needle by using syringe pumps (KD Scientific Model 100, Holliston, MA, USA) at a feed rate of $1 \mathrm{ml} \mathrm{h}^{-1}$. The tip of the metallic needle was connected to a high-voltage power supply (Chargemaster CH30P, SIMCO, Santa Clara, CA, USA) and set at $7.7 \mathrm{kV}$. A flat aluminum foil and quartz was placed $15 \mathrm{~cm}$ below the tip of the needle (working distance) to collect the nanofibers for $30 \mathrm{~min}$. All the experiments were conducted at room temperature and a relative humidity of approximately $30 \%$. The ES nanofibers were annealed at $100{ }^{\circ} \mathrm{C}$ for
$24 \mathrm{~h}$ in an oven for chemical cross-linking, as described by Chiu's group ${ }^{47}$ and our previous report. ${ }^{43,44}$ ES nanofibers from P2 blended with 1, 3 and 5\% bpyF-bpy were denoted P2-1, P2-3 and P2-5, respectively.

Fluorescence and conductivity measurements for sensing metal ion solutions

Each metal ion titration experiment was initiated using a $3.0 \mathrm{ml}$ bpy-F-bpy probe solution (in THF) with a concentration of approximately $10^{-5} \mathrm{M}$. All metal ion solutions were diluted from standard solutions with a concentration of approximately $10^{-2} \mathrm{M}$, and the titration method was similar to that reported in a previous paper. ${ }^{6}$ The changes in all UV-vis absorption and PL spectra of the bpy-F-bpy probe solution resulting from the addition of the aforementioned metal ion solutions at room temperature were measured using a UV-vis spectrophotometer (Hitachi U-4100, Tokyo, Japan) and Fluorolog-3 spectrofluorometer (Horiba Jobin Yvon, Edison, NJ, USA), respectively. The fabricated ES nanofiber membrane was inserted into a quartz cell with its surface facing the excitation light source. The position of the nanofiber membrane was fixed in cuvettes by using adhesive tape, and various metal ion solutions with concentrations of $10^{-7}$ to $10^{-3} \mathrm{M}$ were then added to measure PL change, as described in our previous papers. ${ }^{37,39,40}$ To measure the filter efficiency of the nanofiber membrane, a cycling microfluidics system was used, and the timedependent change in the conductivity of metal ions in the solution was measured using the Suntex Conductivity/Resistivity Meter SC-2300 Taipei, Taiwan (R.O.C).

\section{Characterization}

${ }^{1} \mathrm{H}$ NMR spectra were obtained at room temperature by using a Bruker AM $300(300 \mathrm{MHz})$ spectrometer and $d$-dimethyl sulfoxide as a deuterated solvent. The molecular weight and molecular weight distribution of poly(HEMA-coNMA) were determined by performing GPC by using a Lab Alliance RI2000 instrument (two column, MIXED-C and -D from Polymer Laboratories, Milford, MA, USA) connected to a Schambeck SFD Gmbh refractive index detector. All GPC analyses were performed using a polymer/N,N-dimethylformamide solution at a flow rate of $1 \mathrm{ml} \mathrm{min}{ }^{-1}$ and $70^{\circ} \mathrm{C}$, and calibrated using polystyrene. A Perkin-Elmer 7 thermogravimetric analyzer (TA Instruments, Inc., New Castle, DE, USA) was used in a heating range of 100 to $800^{\circ} \mathrm{C}$ and at a heating rate of $10^{\circ} \mathrm{C} \mathrm{min}^{-1}$. The viscosities of the polymer solutions used for electrospinning were measured using the TA-AR2000ex. The shear viscosities were recorded in the frequency sweep mode at room temperature $\left(25^{\circ} \mathrm{C}\right)$ by using a parallel plate (diameter: $40 \mathrm{~mm}$; gap: $0.075 \mathrm{~mm}$ ). A solvent trap was used around the sample during measurements.

The morphologies of ES nanofibers were characterized using an FE-SEM. Images were captured at an accelerating voltage of $15 \mathrm{kV}$. Before imaging, the samples were sputtered with $\mathrm{Au} / \mathrm{Pt}$. Fluorescence optical microscope images were captured using a two-photon laser confocal microscope (Leica LCS SP5, Wetzlar, Germany).

\section{Theoretical calculation}

All molecular orbital (MO) and time-dependent density functional theory calculations for UV-vis regions were performed using the ORCA package. ${ }^{48}$ The relativistic effect with zeroth-order regular approximation was included in all the calculations. The coordinates used for optimizing the geometry of complexes were initially set in the Avogadro program ${ }^{49}$ and optimized using PM6 parameters in the G09 program. ${ }^{50}$

The geometry was further optimized using the BP86 exchange function in the ORCA program. The def2-TZVP(-f) basis set was used for $\mathrm{Cu}, \mathrm{Zn}, \mathrm{N}, \mathrm{O}, \mathrm{C}$ and $\mathrm{H}$, but the def2-aug-TZVPP basis set was used for Hg. The electronic structure and time-dependent density functional theory calculations were performed using the B3LYP exchange function with the basis set used for geometry optimization. Isosurface plots of the MOs were generated using Molekel Version 4.3 with an isovalue surface at 0.04 a.u. 


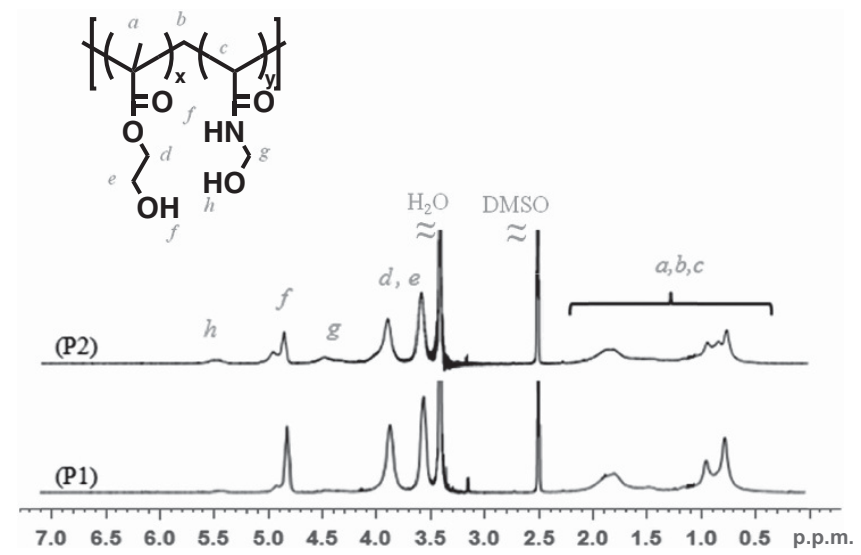

Figure $2{ }^{1} \mathrm{H}$ NMR spectra of poly(HEMA-co-NMA) random copolymers in DMSO. DMSO, dimethyl sulfoxide; HEMA, 2-hydroxyethyl methacrylate; NMA, $\mathrm{N}$-methylolacrylamide. A full color version of this figure is available at Polymer Journal online.

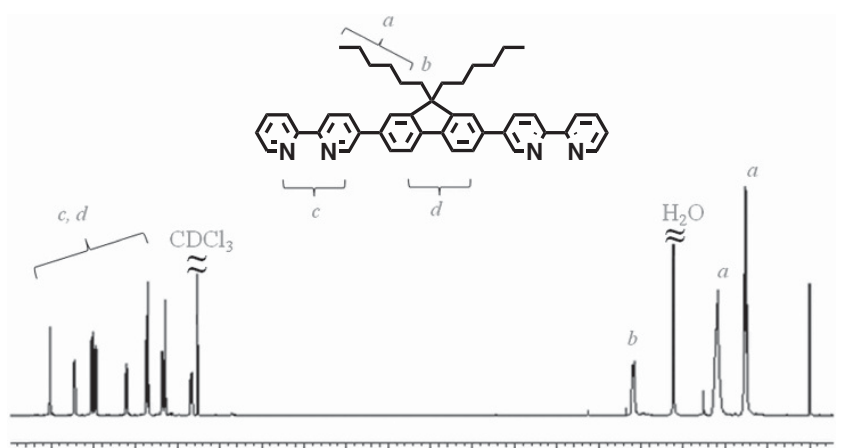

$\begin{array}{llllllllllllllllllll}9.0 & 8.5 & 8.0 & 7.5 & 7.0 & 6.5 & 6.0 & 5.5 & 5.0 & 4.5 & 4.0 & 3.5 & 3.0 & 2.5 & 2.0 & 1.5 & 1.0 & 0.5 & \text { p.p.m. }\end{array}$

Figure $3{ }^{1} \mathrm{H}$ NMR spectra of bpy-F-bpy in $\mathrm{CDCl}_{3}$. bpy-F-bpy, 9,9dihexylfluorene-2,7-bipyridine. A full color version of this figure is available at Polymer Journal online.

\section{RESULTS AND DISCUSSION}

Characterization of poly(HEMA-co-NMA) and bpy-F-bpy

The random poly(HEMA-co-NMA) copolymers with different monomer ratios were denoted $\mathbf{P 1}$ and $\mathbf{P 2}$, as listed in Table 1. P1 and $\mathbf{P} 2$ were obtained through simultaneous free-radical polymerization of HEMA and NMA by using AIBN as an initiator (Scheme 1a). The feeding molar ratios of the two monomers (HEMA: NMA) were 10:1 and 10:3 for P1 and P2, respectively; thus, random copolymers with different NMA compositions were prepared. The effect of the NMA molar fraction on the thermal cross-linking behavior of ES nanofibers was investigated. Table 1 lists the molecular characteristics of poly(HEMA-co-NMA). The chemical structure and composition were characterized using ${ }^{1} \mathrm{H}$ NMR spectra (Figure 2), with the signals being attributed to PHEMA ( $\delta=4.8$ p.p.m., peak f) and PNMA $(\delta=5.4$ p.p.m., peak h). The molar ratios of HEMA to NMA were 90:10 and 77:23 for $\mathbf{P 1}$ and $\mathbf{P 2}$, respectively. The results reveal that the compositions of copolymers could be manipulated by adjusting the feeding molar ratio of monomers in free-radical polymerization. The molecular weight and polydispersity index were studied using GPC (Table 1). The metal-ion-sensitive fluorescent probe, bpy-F-bpy (6), was synthesized through the Suzuki coupling reaction between 9,9-dihexylfluorene-2,7-diboronic acid (4) and 5-bromo-2,2-

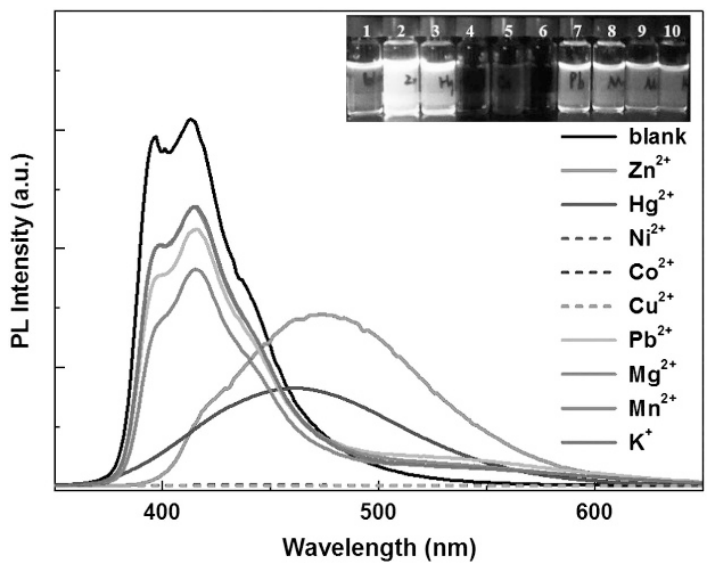

Figure 4 Variation of PL spectra of bpy-F-bpy in a THF solution $\left(10^{-5} \mathrm{M}\right.$, $\mathrm{pH} 7$ ) with different metal ions at $10^{-4} \mathrm{M}$. The corresponding inset figures show color changes under $254 \mathrm{~nm}$ UV light (Sample 1 is a blank and Samples 2-10 are $\mathrm{Zn}^{2+}, \mathrm{Hg}^{2+}, \mathrm{Ni}^{2+}, \mathrm{Co}^{2+}, \mathrm{Cu}^{2+}, \mathrm{Pb}^{2+}, \mathrm{Mg}^{2+}, \mathrm{Mn}^{2+}$ and $\mathrm{K}^{+}$, respectively.). bpy-F-bpy, 9,9-dihexylfluorene-2,7-bipyridine; $\mathrm{PL}$, photoluminescence; THF, tetrahydrofuran. A full color version of this figure is available at Polymer Journal online.

bipyridine (5) (Scheme 1b). The ${ }^{1} \mathrm{H}$ NMR spectra (Figure 3) illustrate the successful synthesis of bpy-F-bpy. This fluorescent probe is composed of two 2,2'-bipyridine units that serve as metalrecognizing sites and a fluorene moiety that serves as a fluorogen.

Figure 4 shows the PL spectra of bpy-F-bpy in a THF solution containing different types of metal ions at a concentration of $10^{-4} \mathrm{M}$ and excited at $340 \mathrm{~nm}$. The probe exhibited bright and sky-blue fluorescence in the THF solution (blank) with emission peaks at 394 and $414 \mathrm{~nm}$. The fluorescence intensity was slightly quenched by adding $\mathrm{K}^{+}, \mathrm{Mn}^{2+}, \mathrm{Mg}^{2+}$ or $\mathrm{Pb}^{2+}$ ions. Severe quenching of the intensity and red shifts of the emission peak to around $480 \mathrm{~nm}$ were observed when the probe was mixed with $\mathrm{Hg}^{2+}$ and $\mathrm{Zn}^{2+}$ ions. Complete quenching of fluorescence was observed when the probe was chelated by $\mathrm{Ni}^{2+}, \mathrm{Co}^{2+}$ or $\mathrm{Cu}^{2+}$ ions.

Figure 5 depicts PL spectra of the titration of bpy-F-bpy in a THF solution by three metal ions at concentrations varying from $5 \times 10^{-7}$ to $5 \times 10^{-4} \mathrm{M}$, and the corresponding UV-vis spectra are shown in the inset figure. For the titration of the probe with $\mathrm{Zn}^{2+}$ ions (Figure $5 \mathrm{a}$ ), the fluorescence intensity decreased as the ion concentration increased initially, and an additional fluorescence band was observed when the ion concentration reached $10^{-5} \mathrm{M}$. The fluorescence of the probe was completely shifted to the additional band when the ion concentration was higher than $5 \times 10^{-5} \mathrm{M}$. For the titration of the probe with $\mathrm{Hg}^{2+}$ ions (Figure $5 b$ ), the fluorescence spectra showed quenching and redshift behavior similar to those of the titration with $\mathrm{Zn}^{2+}$ ions; however, the red shift of the fluorescence peak was observed at a higher ion concentration of $10^{-4} \mathrm{M}$. For the titration of the probe with $\mathrm{Cu}^{2+}$ ions (Figure 5c), the fluorescence was quenched as the ion concentration increased, and the fluorescence peak did not shift. The UV-vis spectra of all titrations exhibited a red shift in the absorption peak maximum as the concentration of metal ions was increased, as illustrated in their respective inset figures.

Simulated UV-vis spectra of bpy-F-bpy and its binding with $\mathrm{Zn}^{2+}$, $\mathrm{Hg}^{2+}$ and $\mathrm{Cu}^{2+}$ are depicted in Figures 6a-d, respectively. Experimental UV-vis spectra with saturated concentrations of metal ions were used for comparison with the time-dependent density functional theory calculations. The results indicate that the absorption bands at approximately $350-380 \mathrm{~nm}$ are mainly related to the transition from 

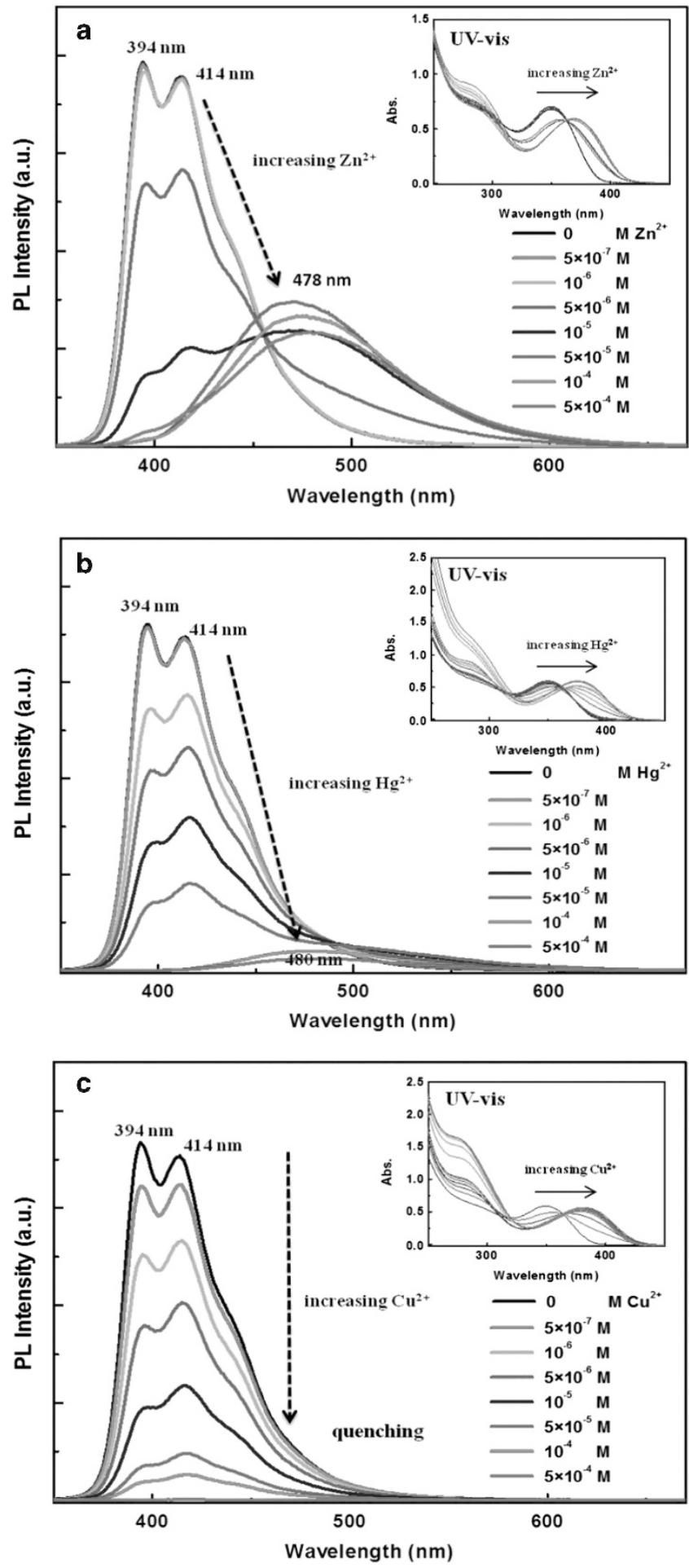

Figure 5 Variation in the PL spectra of the titration of bpy-F-bpy in a THF solution containing (a) $\mathrm{Zn}^{2+}$, (b) $\mathrm{Hg}^{2+}$ and (c) $\mathrm{Cu}^{2+}$ at concentrations varying from $5 \times 10^{-7}$ to $5 \times 10^{-4} \mathrm{M}$. All of the inset figures show the corresponding UV-vis spectra of bpy-F-bpy in the THF solution under the aforementioned conditions. bpy-F-bpy, 9,9-dihexylfluorene-2,7-bipyridine; $\mathrm{PL}$, photoluminescence; THF, tetrahydrofuran. A full color version of this figure is available at Polymer Journal online.

the highest occupied $\mathrm{MO}(\mathrm{HOMO})$ to the lowest unoccupied $\mathrm{MO}$ (LUMO). Overall, the major contributions to the HOMO and LUMO are provided by the fluorene and bpy units, respectively. Close examination of the HOMO and LUMO with and without chelating metal ions revealed that the electrons in the HOMO and LUMO are distributed across the entire metal-free bpy-F-bpy ligand, but become localized on fluorene and bpy units when the ligand binds with metal ions. This effect is particularly obvious in the $\mathrm{Zn}^{2+}$ chelating compound, indicating that this compound has a charge-transfer excited-state characteristic. In Figure 6d, which shows the spectra of the $\mathrm{Cu}^{2+}$ complex, the minor contributions of $3 d$ orbitals in MO263 $\alpha$ indicate that the transition involves partial metal-to-ligand charge transfer. Table 2 lists the energy gaps $\Delta E\left(E_{\mathrm{LUMO}}-E_{\mathrm{HOMO}}\right)$ of all compounds, and the calculation results indicate that the energy levels of MOs decrease substantially as bpy-F-bpy binds to metal ions and the energy gap $\Delta E$ decreases; consequently, red shift effects are observed in absorption spectra. This explains the ionochromic and red-shift effects in the UV-vis titration curves depicted in the inset of Figure 5. Moreover, the smaller energy gap in $\mathrm{Hg}^{2+}$ compared with that in $\mathrm{Zn}^{2+}$ is consistent with the relatively larger red-shift effects observed in absorption spectra. This is owing to the average Mulliken charge of $\mathrm{Hg}^{2+}(\sim 0.83)$ being greater than that of $\mathrm{Zn}^{2+}(\sim 0.50)$, reducing the HOMO-LUMO gaps. These results are consistent with those obtained by Tian et al. ${ }^{25}$ in a simulation by increasing the charge at metal sites.

In the PL spectra depicted in Figure 5, the strong blue emission can be attributed to $\pi \rightarrow \pi^{\star}$ transitions in the bpy-F-bpy ligand. ${ }^{25}$ Chelation with metal ions, except $\mathrm{Cu}^{2+}$, induces a substantial decrease in the blue emission bands and an increase in a new emission band at approximately $480 \mathrm{~nm}$. This new emission band could be owing to the energy levels newly induced by $\mathrm{Zn}^{2+}$ and $\mathrm{Hg}^{2+}$ chelation. The complete intensity quenching in the $\mathrm{Cu}^{2+}$ case could be attributed to the existence of unpaired electrons in the open shell system of $\mathrm{Cu}^{2+}$ complexes. Wang and Wasielewski ${ }^{22}$ reported similar phenomena.

\section{Morphology of electrospun nanofibers}

Figure 7 shows SEM images of the ES nanofibers prepared from P1, $\mathbf{P 2}$ and P2-5. Note that ES nanofibers from P2 blended with 1, 3 and 5\% bpy-F-bpy were denoted $\mathbf{P} \mathbf{2}-\mathbf{1}, \mathbf{P} \mathbf{2}-\mathbf{3}$ and $\mathbf{P} \mathbf{2}-\mathbf{5}$, respectively. The inset figure shows an enlarged FE-SEM image of the nanofibers. In the initial state (no cross-linking or un-immersion in water), the diameter ranges of the as-prepared ES nanofibers from $\mathbf{P 1}, \mathbf{P} 2$ and $\mathbf{P 2}-\mathbf{5}$ were estimated to be $250 \pm 62,500 \pm 111$ and $502 \pm 98 \mathrm{~nm}$, respectively. The average diameter value was calculated using a statistical average of 50 fibers from each sample; this calculation method is similar to that described in our previous report. ${ }^{6}$ The diameter of the P1 nanofibers was markedly smaller than that of the $\mathbf{P} 2$ nanofibers, possibly because the molecular weight and, thus, viscosity of P1 $\left(1.4 \times 10^{-3} \mathrm{~kg}(\mathrm{~m} \cdot \mathrm{s})^{-1}\right)$ are lower than those of $\mathbf{P} 2\left(6.6 \times 10^{-3} \mathrm{~kg}\right.$ $\left.(\mathrm{m} \cdot \mathrm{s})^{-1}\right)$, as illustrated in Table 1 , even though they were both dissolved at the same polymer concentration in the same solvent. However, the diameters of the $\mathbf{P 2}$ and $\mathbf{P 2}-\mathbf{5}$ nanofibers were similar because blending 5\% bpy-F-bpy into the $\mathbf{P} 2$ polymer does not affect the fiber diameter. Although rapid evaporation of the low-boilingpoint solvent $(\mathrm{MeOH})$ and subsequent rapid solidification during electrospinning yields a porous structure, all of the ES nanofibers from the $\mathrm{MeOH}$ solvent were smooth and nonporous because the relative humidity was maintained at approximately 30\% throughout electrospinning, as described in the literature. ${ }^{48}$ As-prepared ES nanofibers that were not subjected to cross-linking but immersed in water were dissolved by the water, and the aluminum substrate exhibited a smooth surface in the wet state (not cross-linked), as shown in the SEM images. The effects of different NMA molecular ratios on the ES fiber morphology after cross-linking and the 

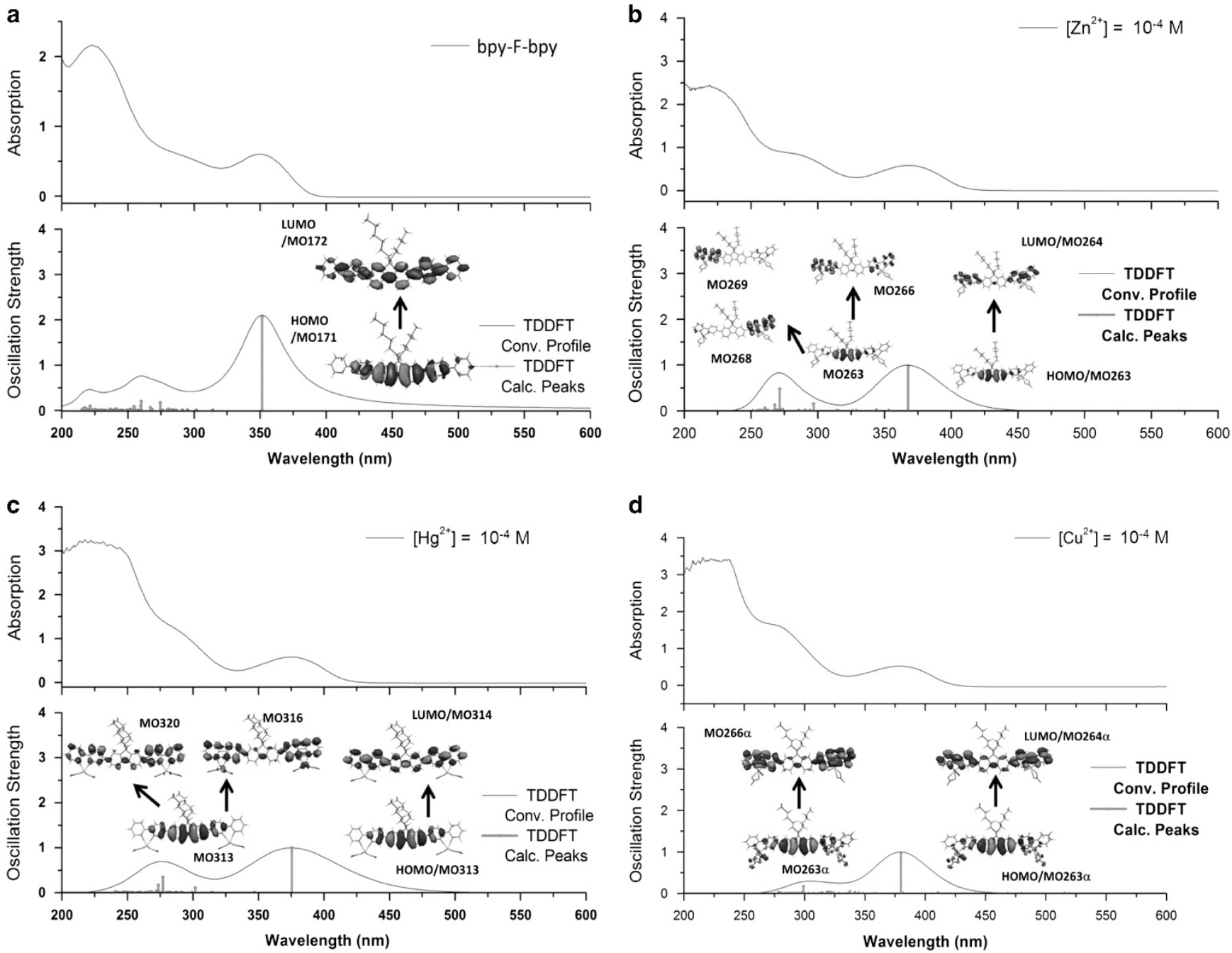

Figure 6 Simulated UV-vis spectra of (a) bpy-F-bpy in a THF solution and its binding with (b) $\mathrm{Zn}^{2+}$, (c) $\mathrm{Hg}^{2+}$ (d) and $\mathrm{Cu}^{2+}$ at a concentration of $5 \times 10^{-4} \mathrm{M}$. bpy-F-bpy, 9,9-dihexylfluorene-2,7-bipyridine; HOMO, highest occupied molecular orbital; LUMO, lowest unoccupied molecular orbital; TDDFT, timedependent density functional theory; THF, tetrahydrofuran. A full color version of this figure is available at Polymer Journal online.

Table 2 Energy gap between the HOMO and LUMO in all calculated compounds

\begin{tabular}{lcccc}
\hline Compound & bpy-F-bpy & $\mathrm{Zn}^{2+}$ & $\mathrm{Hg}^{2+}$ & $\mathrm{Cu}^{2+}$ \\
\hline$\Delta E\left(E_{\mathrm{LUMO}}-E_{\mathrm{HOMO}}\right)(\mathrm{eV})$ & 3.8492 & 3.3625 & 3.3304 & 3.1357 \\
\hline
\end{tabular}

Abbreviations: bpy-F-bpy, 9,9-dihexylfluorene-2,7-bipyridine; HOMO, highest occupied molecular orbital; LUMO, lowest unoccupied molecular orbital.

formation of hydrogel-like nanofibers in water were investigated using an NMA moiety and a heating process. After the as-prepared ES fibers were cross-linked when heated at $100^{\circ} \mathrm{C}$ for $24 \mathrm{~h}$, the diameter and morphology of the fibers did not change, as illustrated in Supplementary Figure S1. The cross-linked P1, P2 and P2-5 ES fibers were estimated to be $257 \pm 51,511 \pm 93$ and $522 \pm 88 \mathrm{~nm}$, respectively. The mechanism of the intermolecular cross-linking reaction of NMA is shown in Supplementary Scheme S1 of the Supplementary Information. Furthermore, after a fixed cross-linking duration, fiber mats were flushed with water approximately 10 times at $30{ }^{\circ} \mathrm{C}$ and then dried at the same temperature by using a vacuum pump. Figure 7 depicts their morphologies in the wet state (cross-linked). The P1 ES nanofibers developed an uneven and porous film-like structure after being extracted using water, suggesting that the cross-linkable PNMA moiety of $\mathbf{P 1}$ can resist the solubility of water after cross-linking, but the amount of NMA incorporated is too low to maintain a stable fiber shape. However, the P2 and P2-5 ES nanofibers exhibited a good fiber morphology with cylinder confinement, enabling them to maintain a high surface-to-volume ratio for response in water environments. This observation indicates that the stability of the nanofibers (or degree of cross-linking) was enhanced as the amount of the NMA moiety was increased and when the cross-linking duration was suitable. ${ }^{49}$ Conversely, the diameters of the P2 and P2-5 ES nanofibers increased to approximately $1000 \mathrm{~nm}$, which is two times greater than their diameter in the initial state. This observation suggests that the cross-linked P2 and P2-5 ES nanofibers exhibited a swelling fiber morphology because their HEMA has a superhydrophilic property and, therefore, absorbs water. This beneficial hydrophilic property enhances the efficiency of the P2-5 ES nanofibers in absorbing metal ions in water.

\section{Sensing property of electrospun nanofibers}

Figure 8a depicts the variation in PL spectra of the P2-5 ES nanofibers in the presence of cations in water at a concentration of $10^{-3} \mathrm{M}$ and 


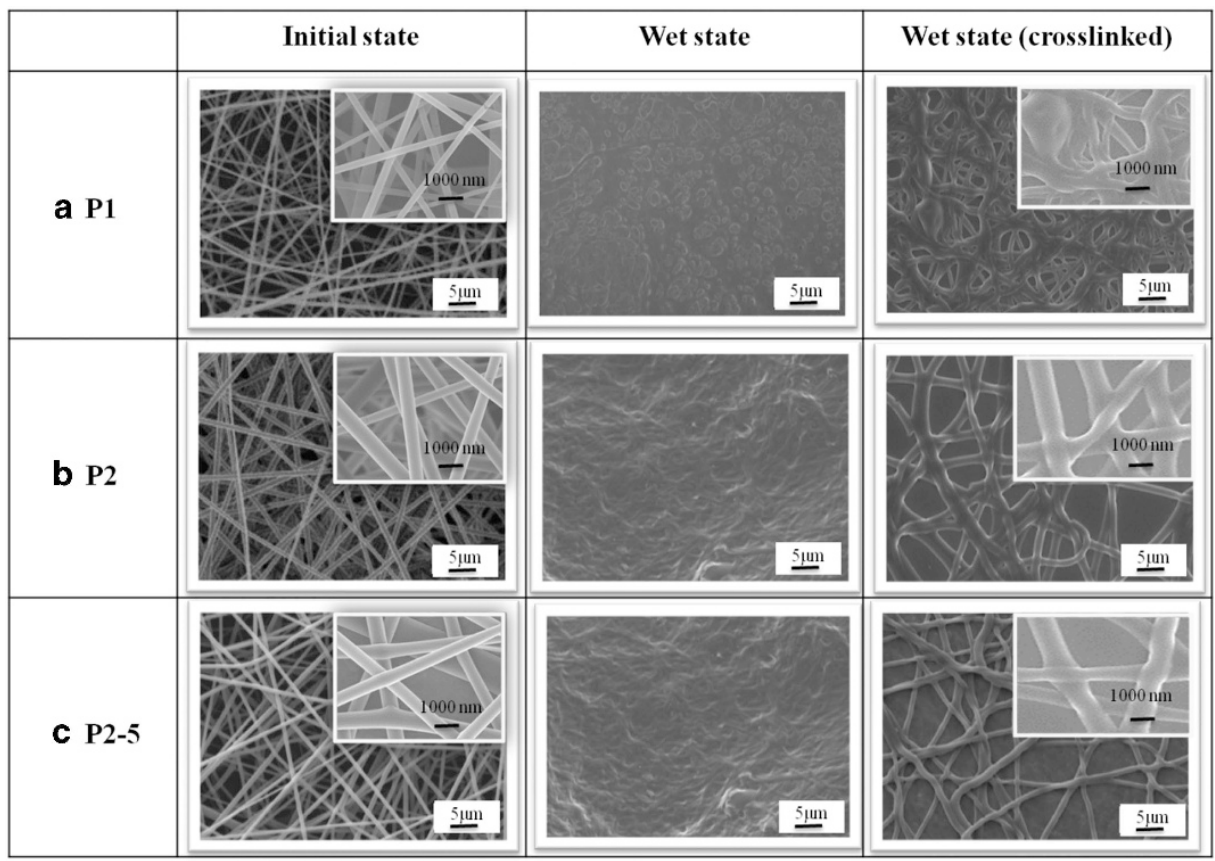

Figure 7 FE-SEM images of (a) P1, (b) P2 and (c) P2-5 ES nanofibers in the initial state (dry state without cross-linking), wet state with no cross-linking and wet state after cross-linking. ES, electrospun; FE-SEM, field-emission scanning electron microscope. A full color version of this figure is available at Polymer Journal online.

excited at $340 \mathrm{~nm}$. The measurement results shown in Figure $8 \mathrm{a}$ and summarized in Figure $8 \mathrm{~b}$ illustrate that the $\mathrm{x}$ axis and $\mathrm{y}$ axis correspond to a shift in the emission maximum $\left(\Delta \lambda^{\mathrm{PL}}{ }_{\max }\right)$ and the PL intensity decreases with respect to that in the PL spectra of nanofibers that are not in the presence of metal ions. As shown in Figure 8, according to the spectroscopic effects of metal ions on bpy-F-bpy, the metal ions can be categorized into three groups. The first group of metal ions $\left(\mathrm{Zn}^{2+}\right.$ and $\left.\mathrm{Hg}^{2+}\right)$ yields substantial red-shift performance but does not markedly quench the fluorescence of the P2-5 ES nanofibers. The range of the red shift in the emission spectra $\left(\Delta \lambda^{\mathrm{PL}}\right.$ max $)$ depends on the metal ion. The $\Delta \lambda^{\mathrm{PL}}$ max of $\mathrm{Zn}^{2+}$ is $70 \mathrm{~nm}$, which is higher than that of $\mathrm{Hg}^{2+}, 40 \mathrm{~nm}$. The second group of metal ions, consisting of $\mathrm{Ni}^{2+}, \mathrm{Co}^{2+}$ and $\mathrm{Cu}^{2+}$, quenches the fluorescence of the P2-5 ES nanofibers completely or nearly completely. The final group of metal ions, comprising $\mathrm{K}^{+}, \mathrm{Mn}^{2+}, \mathrm{Mg}^{2+}$ and $\mathrm{Pb}^{2+}$ ions, only slightly quenches the fluorescence intensity. These results demonstrate that the P2-5 ES nanofibers exhibit different photophysical properties when they detect different metal ions and, therefore, can be used as metal ion sensors.

Figures $9 \mathrm{a}-\mathrm{c}$ shows the change in the fluorescence spectra of the P2-5 ES nanofibers as a function of different concentrations of $\mathrm{Zn}^{2+}$, $\mathrm{Hg}^{2+}$ and $\mathrm{Cu}^{2+}$, respectively. Images of the corresponding P2-5 ES nanofibers vary with the concentration value under UV irradiation $(365 \mathrm{~nm})$, as illustrated in the inset figure. Under the initial condition with no metal ions, the PL spectra of the P2-5 ES nanofibers exhibited a main emission peak corresponding to an emission maximum $\left(\lambda^{\mathrm{PL}}{ }_{\text {max }}\right)$ of approximately $450 \mathrm{~nm}$, which is attributed to the bpy-F-bpy. Figure 9a shows that the P2-5 ES nanofibers exhibited a high sensitivity for $\mathrm{Zn}$ in the $10^{-7}-10^{-3} \mathrm{M}$ response range. In contrast to the colors in the original state (without $\mathrm{Zn}^{2+}$ ), the emission colors markedly changed as the concentration of $\mathrm{Zn}^{2+}$ was increased. As Figure 9a illustrates, increasing the $\mathrm{Zn}^{2+}$ concentration reduced the PL intensity and caused a red shift in the emission of the ES nanofibers. A red shift in the emission maximum $\left(\lambda^{\mathrm{PL}}\right.$ max $)$ from 450 to $520 \mathrm{~nm}$ indicated sensitivity for $\mathrm{Zn}^{2+}$. The $\mathrm{Zn}^{2+}$ concentration at which the PL intensity began to decrease was $10^{-7} \mathrm{M}$, suggesting that the ES nanofibers exhibited a high sensitivity for $\mathrm{Zn}^{2+}$. The emission maximum of the ES nanofibers substantially shifted from $450 \mathrm{~nm}$ in $0 \mathrm{M} \mathrm{Zn}^{2+}$ to $520 \mathrm{~nm}$ in $10^{-3} \mathrm{M} \mathrm{Zn}^{2+}$. The considerable red shift in the emission peaks, high $\Delta \lambda_{\max }(70 \mathrm{~nm})$, and change in the luminescence color from blue $(450 \mathrm{~nm})$ to green $(520 \mathrm{~nm})$ indicate the high sensitivity for $\mathrm{Zn}^{2+}$. Similar $\Delta \lambda_{\max }$ red-shifting by $34 \mathrm{~nm}$ was observed for the ES nanofibers chelated with $\mathrm{Hg}^{2+}$, as Figure 9b illustrates. However, compared with $\mathrm{Zn}^{2+}$ sensing, the shift of $\Delta \lambda_{\max }$ decreased from 70 to $34 \mathrm{~nm}$ in $\mathrm{Hg}^{2+}$ sensing. The greater shift of $\Delta \lambda_{\max }$ in $\mathrm{Zn}^{2+}$ sensing than in $\mathrm{Hg}^{2+}$ sensing may be partially attributed to the smaller element size of $\mathrm{Zn}^{2+}$, which leads to more efficient chelation by bpy-F-bpy and promotes metal ion sensing characteristics. Conversely, Figure $9 \mathrm{c}$ shows that the fluorescence intensity decreased as the $\mathrm{Cu}^{2+}$ concentration was increased. This fluorescence intensity decrease was expected and believed to be owing to the quenching of the bpy-F-bpy indicator by $\mathrm{Cu}^{2+}$. The fluorescence quenching is owing to the interactions between the electron-rich bpy-F-bpy indicator ${ }^{(-)}$and electron-deficient quencher ${ }^{(+)}$, and the degree of quenching depends on the amount of $\mathrm{Cu}^{2+} \cdot 10$

Figure 10 shows a laser confocal image of the P2-5 ES nanofibers in the presence of no metal ions, $10^{-3} \mathrm{M} \mathrm{Hg}^{2+}$ and $10^{-3} \mathrm{M} \mathrm{Zn}^{2+}$, respectively. These nanofibers had visually distinguishable luminescence colors of blue, blue-green and green, suggesting that they can become efficient sensory materials for detecting various metal ions. The P2-5 ES nanofibers exposed to $10^{-3} \mathrm{M} \mathrm{Zn}^{2+}$ exhibited apparent color change from blue to green. In addition, the porous structure of ES nonwoven fibers can be applied in filters for purifying water containing heavy metal ions. Therefore, the P2-5 ES nanofibers can serve as both smart sensors and efficient filters. The experimental results pertaining to these nanofibers are discussed in the following paragraphs. 

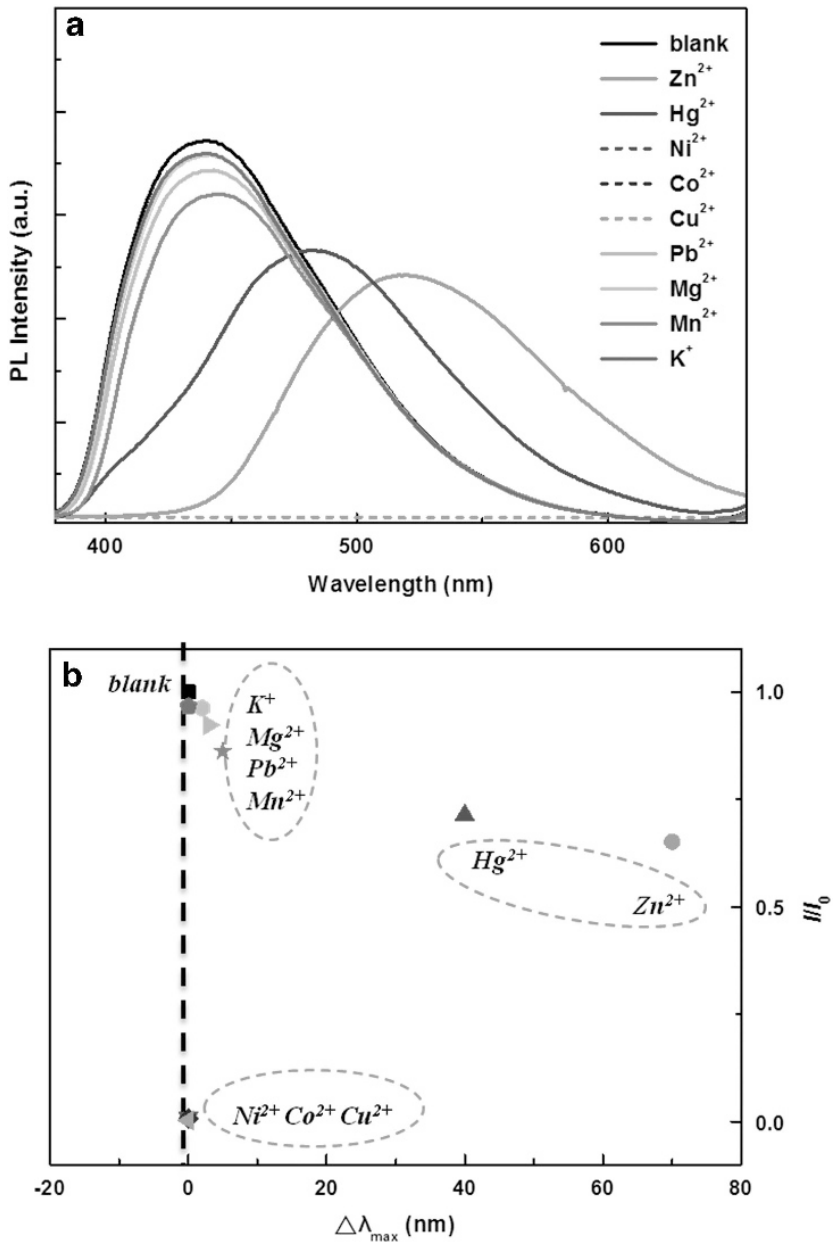

Figure 8 (a) Variation in the PL spectra of P2-5 ES nanofibers used for sensing various metal ions at a concentration of $10^{-3} \mathrm{M}$. (b) The $\mathrm{x}$ axis and $y$ axis correspond to the shift in the emission maximum $\left(\lambda_{\max }\right)$ and the enhancement of $\mathrm{PL}$ intensity under the aforementioned condition with respect to the PL spectra of nanofibers not exposed to metal ions. ES, electrospun; PL, photoluminescence. A full color version of this figure is available at Polymer Journal online.

To explore the effect of different blending ratios of bpy-F-bpy on the sensing characteristics of the P2 ES fibers, we summarized the PL spectra of the P2-1, P2-3 and P2-5 ES nanofibers in the presence of $10^{-7}-10^{-3} \mathrm{M} \mathrm{Zn}^{2+}$ excited at $340 \mathrm{~nm}$. The fiber morphology of P2-1 and $\mathbf{P 2 - 3}$ is similar to that of $\mathbf{P 2 - 5}$, as the SEM images in Supplementary Figures S2 and S3 depict, and raw data on the measured PL spectra of the P2-1, P2-3 and P2-5 ES nanofibers are provided in Supplementary Figures $\mathrm{S} 4 \mathrm{a}$ and $\mathrm{b}$ and Figure 9a, respectively. Figure 11a summarizes the PL results of the three nanofibers, showing that increasing the $\mathrm{Zn}^{2+}$ concentration reduced the PL intensity and resulted in a red shift in the emission of the ES nanofibers. A red shift in the emission maximum $\left(\lambda^{\mathrm{PL}}{ }_{\max }\right)$ from 450 to $520 \mathrm{~nm}$ indicated sensitivity for $\mathrm{Zn}^{2+}$. For the P2-5 ES nanofibers, the PL intensity $I_{\mathrm{f}} / I_{0}\left(I_{0}\right.$ denotes the original PL intensity at $450 \mathrm{~nm}$ of $\lambda^{\mathrm{PL}}{ }_{\text {max }}$ and $I_{\mathrm{f}}$ denotes the PL intensity at $520 \mathrm{~nm}$ of $\lambda^{\mathrm{PL}}$ max at $10^{-3} \mathrm{M}$ $\mathrm{Zn}^{2+}$ ) was 1.60 , whereas the $I_{\mathrm{f}} / I_{0}$ values of the P2-3 and P2-1 ES nanofibers were 1.32 and 1.21, respectively, as Figure 11a shows. This observation indicates that the P2-5 ES nanofibers contain a higher amount of bpy-F-bpy than the other nanofibers do, thus yielding
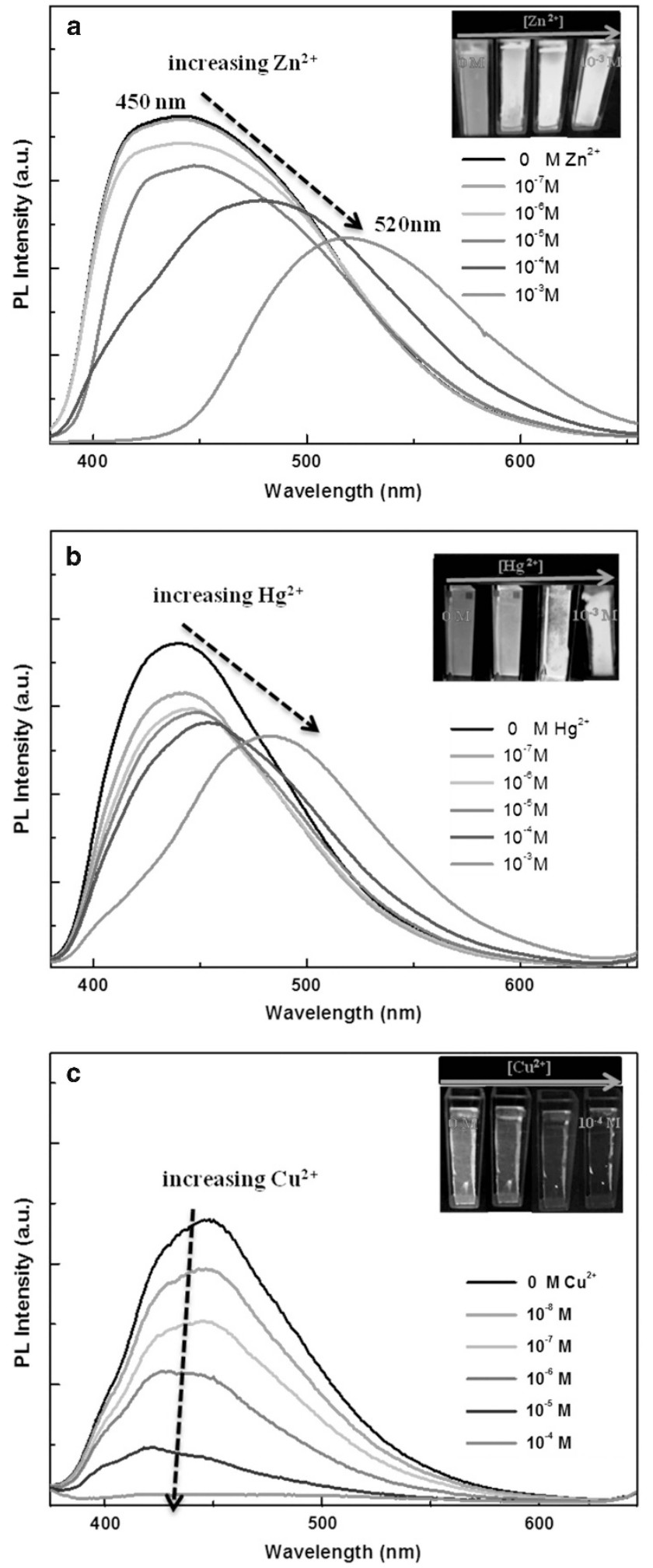

Figure 9 Variation in the PL spectra of P-2 ES nanofibers in aqueous solutions containing (a) $\mathrm{Zn}^{2+}$, (b) $\mathrm{Hg}^{2+}$ and (c) $\mathrm{Cu}^{2+}$ with concentrations varying from $10^{-7}$ to $10^{-3} \mathrm{M}$. All of the inset figures show corresponding photographs recorded under UV light. ES, electrospun; PL, photoluminescence. A full color version of this figure is available at Polymer Journal online. 

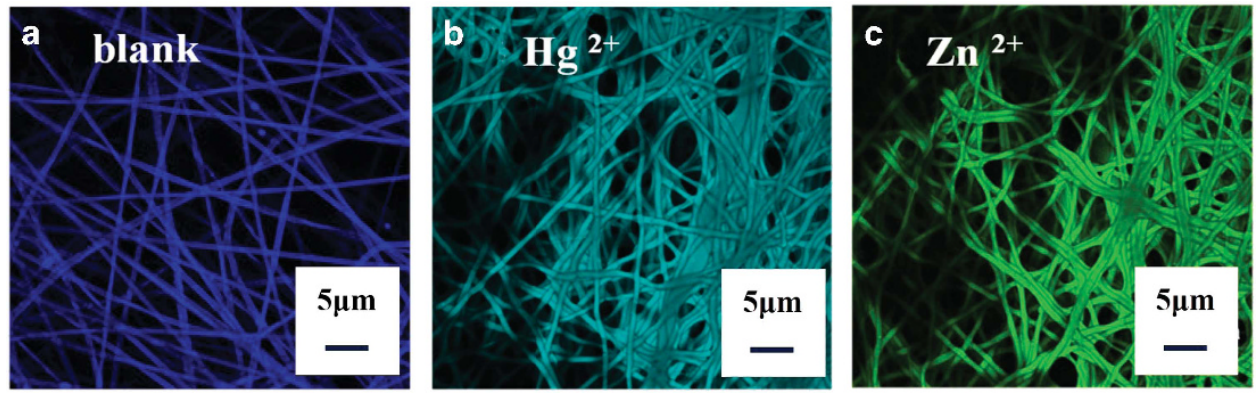

Figure 10 Confocal microscopy images of (a) blank P-2 ES nanofibers and (b) P-2 ES nanofibers used for sensing $\mathrm{Hg}^{2+}$ and (c) $\mathrm{Zn}^{2+}$. ES, electrospun.
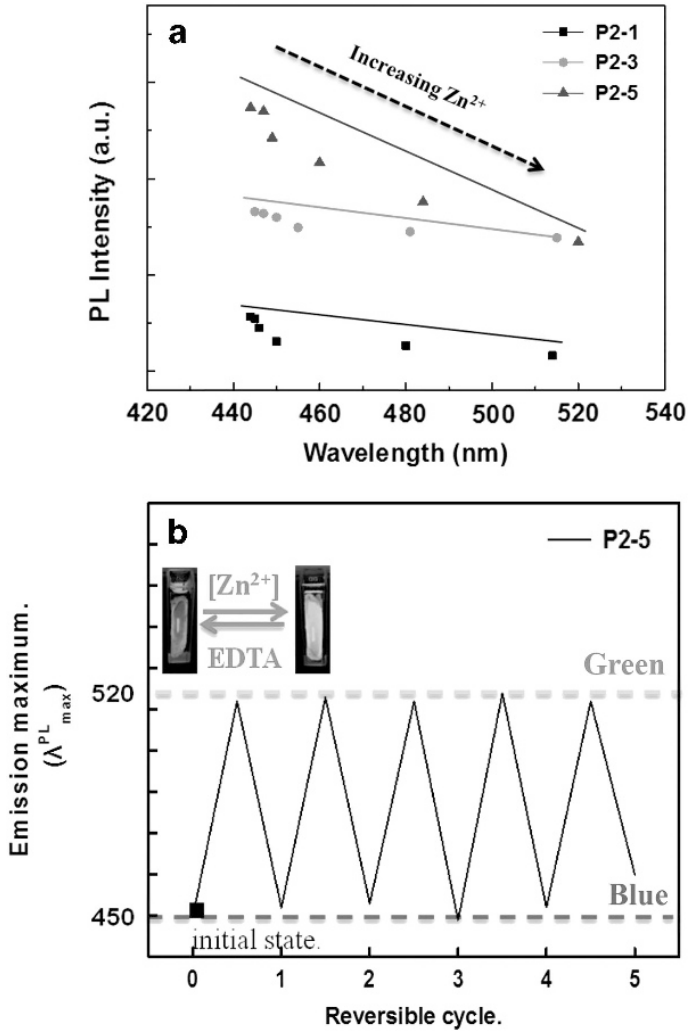

Figure 11 (a) Curves of $\mathrm{PL}$ intensity versus wavelength when the $\mathrm{Zn}^{2+}$ ion concentration was increased from $10^{-7}$ to $10^{-3} \mathrm{M}$. (b) Reversible sensing of $\mathrm{Zn}^{2+}$ ions. (b) Reversibility of the $\mathrm{Zn}^{2+}$-dependent 'on-off-on' fluorescence intensity profile of the P-2 ES nanofibers; the inset figures show corresponding photographs recorded under UV light. EDTA, ethylenediaminetetraacetic acid; ES, electrospun; PL, photoluminescence. A full color version of this figure is available at Polymer Journal online.

higher performance. The results indicate that the bpy-F-bpy composite of the P2-5 ES nanofibers absorbed more $\mathrm{Zn}^{2+}$ than those of the P2-3 and P2-1 nanofibers did, considerably enhancing the $\mathrm{Zn}^{2+}$-sensing efficiency. The $5 \%$ blending ratio of bpy-F-bpy is low, but yielded high sensing performance. Therefore, increasing the blending ratio of bpy-F-bpy can enhance the efficiency of $\mathrm{Zn}^{2+}$ sensing.

Reversibility is another crucial factor determining the usability of sensing nanofibers. Therefore, the variation in the emission maximum $\left(\lambda^{\mathrm{PL}}{ }_{\max }\right)$ of the P2-5 ES nanofibers during a $\mathrm{Zn}^{2+}$-EDTA cycle was tested and is shown in Figure 11b. The original P2-5 ES nanofibers exhibited $\lambda^{\mathrm{PL}}{ }_{\max }$ at $450 \mathrm{~nm}$, emitting blue fluorescence. Chelating $\mathrm{Zn}^{2+}$
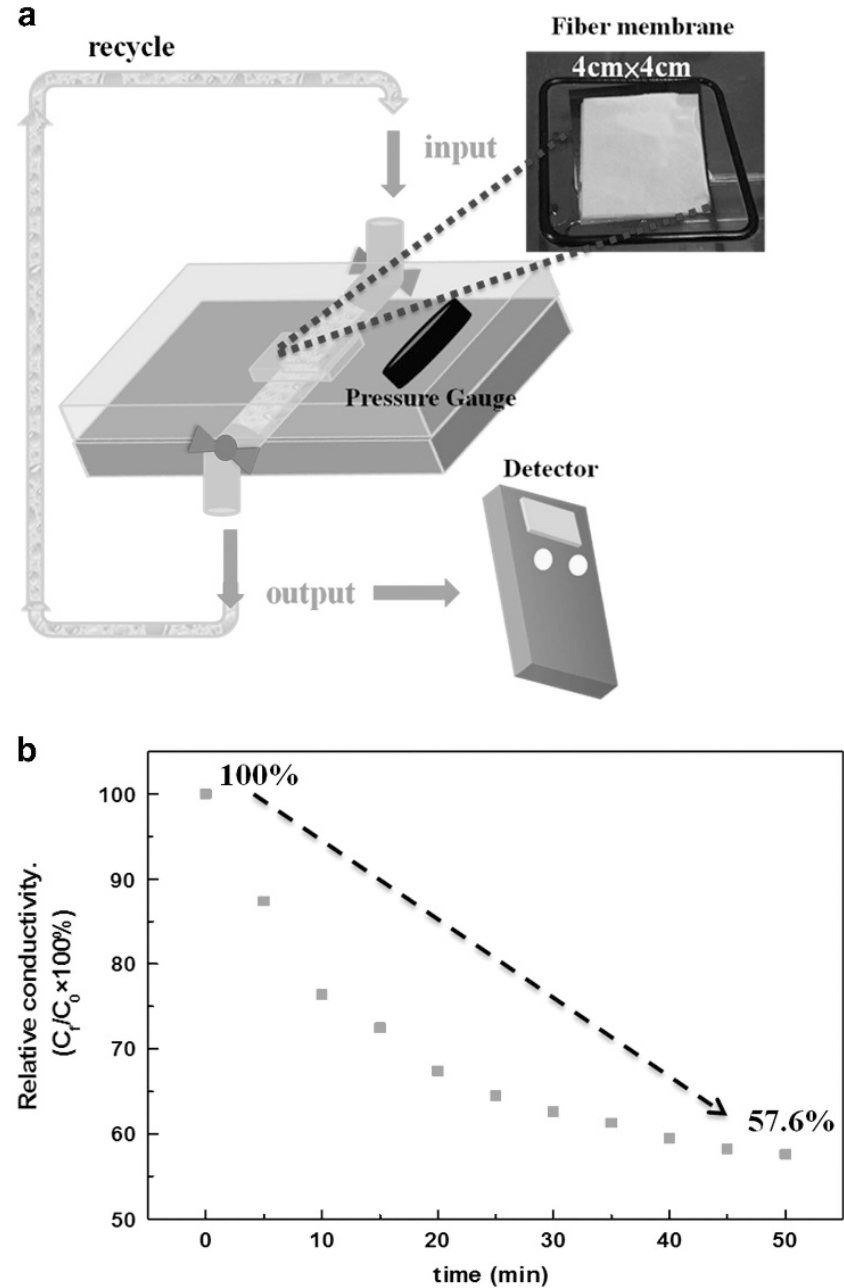

Figure 12 (a) Microfluidics system for examining real-time metal ion sensing by the ES nanofiber membrane. (b) Relative conductivity versus time of P-2 ES nanofibers in the microfluidics system. ES, electrospun. A full color version of this figure is available at Polymer Journal online.

caused the emission peaks of the P2-5 ES nanofibers to red-shift substantially, causing $\Delta \lambda_{\max }$ to be high $(70 \mathrm{~nm})$ and the luminescence color to change from blue $(450 \mathrm{~nm})$ to green $(520 \mathrm{~nm})$. Furthermore, adding EDTA resulted in the fluorescence emission of the P2-5 ES nanofibers considerably switching from green to blue because of the $\mathrm{Zn}^{2+}$ chelation of EDTA from the bpy-F-bpy of the nanofibers. This observation indicates that, on the addition of EDTA, emission is almost completely restored to the original value (blue, $450 \mathrm{~nm}$ ) 
obtained in the absence of $\mathrm{Zn}^{2+}$, which is denoted by Cycle 1. Such on-off switchable fluorescence emission of the P2-5 ES nanofibers in aqueous media on the sequential addition of $\mathrm{Zn}^{2+}$ and EDTA can be cycled at least five times.

Figure 12a depicts a microfluidics system in which a P2-5 ES nanofiber membrane with an area of $16 \mathrm{~cm}^{2}$ set in the middle of a tube is used to rapidly chelate and sense $\mathrm{Zn}^{2+}$ in a solution flowing through the tube. The time-dependent variation of the solution conductivity was tested. The prepared $\mathrm{Zn}^{2+}$ solution contained 1 p.p.m. $\mathrm{Zn}^{2+}\left(7.5 \times 10^{-3}\right.$ mole $\mathrm{Zn}^{2+}$ in 0.5 liter of water $)$. The conductivity of the $\mathrm{Zn}^{2+}$ solution in the initial state $(0 \mathrm{~min})$ was $163.2 \mu \mathrm{S} \mathrm{cm}^{-1}$. As the flow time increased, the solution conductivity decreased to $94.0 \mu \mathrm{S} \mathrm{cm}^{-1}$. Supplementary Table S1 in the Supplementary Information contains raw data on the entire change in conductivity over $50 \mathrm{~min}$, and Figure $12 \mathrm{~b}$ depicts $C_{t} / C_{0}(\%)$ versus time ( $C_{0}$ denotes the original conductivity at $0 \mathrm{~min}$, and $C_{t}$ denotes the conductivity at time $t$ ). As Figure $12 \mathrm{~b}$ shows, the solution conductivity decreased as the flow time increased, indicating that an increasing number of $\mathrm{Zn}^{2+}$ ions were chelated with the P2-5 ES nanofiber membrane, causing less $\mathrm{Zn}^{2+}$ to be present in the solution. Thus, the $100 \%$ conductivity of the solution in the initial state $(0 \mathrm{~min})$ decreased to $57.6 \%$ after $50 \mathrm{~min}$. The rapid conductivity variation is owing to the high surface-to-volume ratio of the ES nanofibers. These results suggest that the studied ES fibers consisting of blends of PHEMA-co-PNMA and bpy-F-bpy have potential for application as efficient and multifunctional sensor filters.

\section{CONCLUSIONS}

New multifunctional ES nanofibers with high sensitivity in detecting various metal ions were prepared by blending poly(NIPAAm-coNMA) copolymers with various amounts of bpy-F-bpy by using a single-capillary spinneret. The HEMA, NMA and bpy-F-bpy moieties were designed to exhibit hydrophilic properties, chemical cross-linking and metal ion sensing ability, respectively. Three types of optical change, namely slightly quenched, red-shifted and completely quenched emission, in bpy-F-bpy used for detecting metal ions in a THF solution were determined according to experimental optical spectra and simulation results. Cross-linked ES nanofibers maintained their fiber structure in water and sensitivity for metal ions because of the sufficient NMA composition. In an aqueous solution containing metal ions, the emission of the ES nanofibers varied from blue (without metal ions) to green $\left(\mathrm{Zn}^{2+}\right)$ to blue-green $\left(\mathrm{Hg}^{2+}\right)$ and was quenched $\left(\mathrm{Cu}^{2+}\right)$. The P2-5 ES nanofibers exhibited the highest $\Delta \lambda_{\max }$ of $70 \mathrm{~nm}$, and the luminescence color changed from blue to green when they were used for detecting $\mathrm{Zn}^{2+}$. Moreover, these nanofibers exhibited substantial reversible dual PL between blue and green in aqueous $\mathrm{Zn}^{2+}$ and EDTA solutions. According to the experimental results obtained using a microfluidics system, the solution conductivity decreased as the flow time increased, indicating that an increasing number of $\mathrm{Zn}^{2+}$ ions in the solution was chelated with the P2-5 ES nanofiber membrane. The high surface-to-volume ratio of the P2-5 ES nanofibrous membranes, which can be used as 'naked eye' sensors, indicates that these membranes have potential for application in multifunctional environment chemosensor-filtering devices.

\section{CONFLICT OF INTEREST}

The authors declare no conflict of interest.

\section{ACKNOWLEDGEMENTS}

The financial support from the Ministry of Science and Technology of Taiwan is highly appreciated.
1 Zhou, Z. \& Fahrni, C. J. A fluorogenic probe for the copper(I)-catalyzed azide-alkyne ligation reaction: modulation of the fluorescence emission via ${ }^{3}\left(n, \pi^{*}\right)-{ }^{1}\left(\pi, \pi^{*}\right)$ inversion. J. Am. Chem. Soc. 126, 8862-8863 (2004).

2 Royzen, M., Dai, Z. \& Canary, J. W. Ratiometric displacement approach to $\mathrm{Cu}(\mathrm{II})$ sensing by fluorescence. J. Am. Chem. Soc. 127, 1612-1613 (2005).

3 Zeng, L., Miller, E. W., Pralle, A., Isacoff, E. Y. \& Chang, C. J. A selective turn-on fluorescent sensor for imaging copper in living cells. J. Am. Chem. Soc. 128, 10-11 (2006).

4 Swamy, K. M. K., Ko, S. K., Kwon, S. K., Lee, H. N., Mao, C., Kim, J. M., Lee, K. H., Kim, J., Shin, I. \& Yoon, J. Boronic acid-linked fluorescent and colorimetric probes for copper ions. Chem. Commun. 5915-5917 (2008).

5 Bag, B. \& Pal, A. Water induced chromogenic and fluorogenic signal modulation in a bi-fluorophore appended acyclic amino-receptor system. Org. Biomol. Chem. 9, 915-925 (2011).

6 Hong, Y., Chen, S., Leung, C. W. T., Lam, J. W. Y., Liu, J., Tseng, N. W., Kwok, R. T. K., Yu, Y., Wang, Z. \& Tang, B. Z. Fluorogenic Zn(II) and chromogenic Fe(II) sensors based on terpyridine-substituted tetraphenylethenes with aggregation-induced emission characteristics. ACS Appl. Mater. Interfaces 3, 3411-3418 (2011).

7 Liu, Y., Sun, Y., Du, J., Lv, X., Zhao, Y., Chen, M., Wang, P. \& Guo, W. Highly sensitive and selective turn-on fluorescent and chromogenic probe for $\mathrm{Cu}^{2+}$ and $\mathrm{ClO}^{-}$based on a $\mathrm{N}$-picolinyl rhodamine B-hydrazide derivative. Org. Biomol. Chem. 9, 432-437 (2011).

8 Liu, W. Y., Li, H. Y., Zhao, B. X. \& Miao, J. Y. A new fluorescent and colorimetric probe for $\mathrm{Cu}^{2+}$ in live cells. Analyst 137, 3466-3469 (2012).

9 Kumari, N., Dey, N., Jha, S. \& Bhattacharya, S. Ratiometric, reversible, and parts per billion level detection of multiple toxic transition metal ions using a single probe in micellar media. ACS Appl. Mater. Interfaces 5, 2438-2445 (2013).

10 Gouanvé, F., Schuster, T., Allard, E., Méallet-Renault, R. \& Larpent, C. Fluorescence quenching upon binding of copper ions in dye-doped and ligand-capped polymer nanoparticles: a simple way to probe the dye accessibility in nano-sized templates. Adv. Funct. Mater. 17, 2746-2756 (2007).

11 Kim, H. J., Lee, S. J., Park, S. Y., Jung, J. H. \& Kim, J. S. Detection of Cull by a chemodosimeter-functionalized monolayer on mesoporous silica. Adv. Mater. 20, 3229-3234 (2008).

$12 \mathrm{Mu}$, L., Shi, W., Chang, J. C. \& Lee, S. T. Silicon nanowires-based fluorescence sensor for Cu(II). Nano Lett. 8, 104-109 (2008).

13 Chen, W., Tu, X. \& Guo, X. Fluorescent gold nanoparticles-based fluorescence sensor for $\mathrm{Cu}^{2+}$ ions. Chem. Commun. 1736-1738 (2009).

14 Liu, D., Wang, Z. \& Jiang, X. Gold nanoparticles for the colorimetric and fluorescent detection of ions and small organic molecules. Nanoscale 3, 1421-1433 (2011).

15 George, A., Shibu, E. S., Maliyekkal, S. M., Bootharaju, M. S. \& Pradeep, T. Luminescent, freestanding composite films of $\mathrm{Au}_{15}$ for specific metal ion sensing. ACS Appl. Mater. Interfaces 4, 639-644 (2012).

16 Ley, K. D., Li, Y., Johnson, J. V., Powell, D. H. \& Schanze, K. S. Synthesis and characterization of $\pi$-conjugated oligomers that contain metal-to-ligand charge transfer chromophores. Chem. Commun. 1749-1750 (1999).

17 McQuade, D. T., Pullen, A. E. \& Swager, T. M. Conjugated polymer-based chemical sensors. Chem. Rev. 100, 2537-2574 (2000).

18 Baskar, C., Lai, Y. H. \& Valiyaveettil, S. Synthesis of a novel optically tunable amphiphilic poly(p-phenylene): influence of hydrogen bonding and metal complexation on optical properties. Macromolecules 34, 6255-6260 (2001).

19 Yang, B., Tian, L., Zhang, H., Zhang, W., Xu, H., Xie, Z., Lu, P., Zhang, M., Yu, J., Lu, D., Ma, Y. \& Shen, J. Nature of zinc(II)-induced ionochromic effect of bipyridinecontaining conjugated polymers: an electrostatic interaction mechanism. J. Phys. Chem. B 110, 16846-16851 (2006).

20 Shiraishi, Y., Miyamoto, R., Zhang, X. \& Hirai, T. Rhodamine-based fluorescent thermometer exhibiting selective emission enhancement at a specific temperature range. Org. Lett. 9, 3921-3924 (2007).

$21 \mathrm{Kim}$, H. N., Guo, Z., Zhu, W., Yoon, J. \& Tian, H. Recent progress on polymer-based fluorescent and colorimetric chemosensors. Chem. Soc. Rev. 40, 79-93 (2011).

22 Wang, B. \& Wasielewski, M. R. Design and synthesis of metal ion-recognition-induced conjugated polymers: an approach to metal ion sensory materials. J. Am. Chem. Soc. 119, 12-21 (1997).

23 Yasuda, T., Yamaguchi, I. \& Yamamoto, T. A new soluble 1,10-phenanthrolinecontaining $\pi$-conjugated polymer: synthesis and effect of metal complexation on optical properties. Adv. Mater. 15, 293-296 (2003).

24 Yasuda, T. \& Yamamoto, T. Synthesis and characterization of new luminescent 1,10phenanthroline- and pyridine-containing $\pi$-conjugated polymers. their optical response to protic acid, $\mathrm{M}^{\mathrm{n}+}$, and solvents. Macromolecules 36, 7513-7519 (2003).

25 Tian, L., Zhang, W., Yang, B., Lu, P., Zhang, M., Lu, D., Ma, Y. \& Shen, J. Zinc(II)induced color-tunable fluorescence emission in the $\pi$-conjugated polymers composed of the bipyridine unit: a way to get white-light emission. J. Phys. Chem. Lett. 109, 6944-6947 (2005)

26 Reneker, D. H. \& Chun, I. Nanometre diameter fibres of polymer, produced by electrospinning. Nanotechnology 7, 216-223 (1996)

27 Babel, A., Li, D., Xia, Y. \& Jenekhe, S. A. Electrospun nanofibers of blends of conjugated polymers: morphology, optical properties, and field-effect transistors. Macromolecules 38, 4705-4711 (2005).

28 Kuo, C. C., Lin, C. H. \& Chen, W. C. Morphology and photophysical properties of lightemitting electrospun nanofibers prepared from poly(fluorene) derivative/PMMA blends. Macromolecules 40, 6959-6966 (2007). 
29 Chae, S. K., Park, H., Yoon, J., Lee, C. H., Ahn, D. J. \& Kim, J. M. Polydiacetylene supramolecules in electrospun microfibers: fabrication, micropatterning, and sensor applications. Adv. Mater. 19, 521-524 (2007)

30 Kuo, C. C., Tung, Y. C., Lin, C. H. \& Chen, W. C. Novel luminescent electrospun fibers prepared from conjugated rod-coil block copolymer of poly[2,7-(9,9-dihexylfluorene)]block-poly(methyl methacrylate). Macromol. Rapid Commun. 29, 1711-1715 (2008).

31 Wang, C. T., Kuo, C. C., Chen, H. C. \& Chen, W. C. Non-woven and aligned electrospun multicomponent luminescent polymer nanofibers: effects of aggregated morphology on the photophysical properties. Nanotechnology 20, 375604 (2009).

$32 \mathrm{Fu}$, G. D., Xu, L. Q., Yao, F., Li, G. L. \& Kang, E. T. Smart nanofibers with a photoresponsive surface for controlled release. ACS Appl. Mater. Interfaces 1, 2424-2427 (2009).

33 Huang, Y. S., Kuo, C. C., Shu, Y. C., Jang, S. C., Tsen, W. C. Chuang, F. S. \& Chen, C. C. Highly aligned and single-layered hollow fibrous membranes prepared from polyurethane and silica blends through a two-fluid coaxial electrospun process. Macromol. Chem. Phys. 215, 879-887 (2014).

34 Wang, X., Kim, Y. G., Drew, C., Ku, B. C., Kumar, J. \& Samuelson, L. A. Electrostatic assembly of conjugated polymer thin layers on electrospun nanofibrous membranes for biosensors. Nano Lett. 4, 331-334 (2004).

35 Yoon, J., Chae, S. K. \& Kim, J. M. Colorimetric sensors for volatile organic compounds (VOCs) based on conjugated polymer-embedded electrospun fibers. J. Am. Chem. Soc. 129, 3038-3039 (2007).

36 Davis, B. W., Niamnont, N., Hare, C. D., Sukwattanasinitt, M. \& Cheng, Q. Nanofibers doped with dendritic fluorophores for protein detection. ACS Appl. Mater. Interfaces 2, 1798-1803 (2010).

37 Kuo, C. C., Tung, Y. C. \& Chen, W. C. Morphology and pH sensing characteristics of new luminescent electrospun fibers prepared from poly(phenylquinoline)-block-polystyrene/ polystyrene blends. Macromol. Rapid Commun. 31, 65-70 (2010).

38 Tzeng, P., Kuo, C. C., Lin, S. T., Chiu, Y. C. \& Chen, W. C. New thermoresponsive luminescent electrospun nanofibers prepared from poly[2,7-(9,9-dihexylfluorene)] block-poly(N-isopropylacrylamide)/PMMA blends. Macromol. Chem. Phys. 211, 1408-1416 (2010).

39 Chiu, Y. C., Kuo, C. C., Hsu, J. C. \& Chen, W. C. Thermoresponsive luminescent electrospun fibers prepared from poly(DMAEMA-co-SA-co-StFI) multifunctional random copolymers. ACS Appl. Mater. Interfaces 2, 3340-3347 (2010).

40 Chiu, Y. C., Chen, Y., Kuo, C. C., Tung, S. H., Kakuchi, T. \& Chen, W. C. Synthesis, morphology, and sensory applications of multifunctional rod-coil-coil triblock copolymers and their electrospun nanofibers. ACS Appl. Mater. Interfaces 4, 3387-3395 (2012).

41 Wang, X., Drew, C., Lee, S. H., Senecal, K. J., Kumar, J. \& Samuelson, L. A. Electrospun nanofibrous membranes for highly sensitive optical sensors. Nano Lett. 2 1273-1275 (2002).
42 Wang, W., Yang, Q., Sun, L., Wang, H., Zhang, C., Fei, X., Sun, M. \& Li, Y. Preparation of fluorescent nanofibrous film as a sensing material and adsorbent for $\mathrm{Cu}^{2+}$ in aqueous solution via copolymerization and electrospinning. J. Hazard. Mater. 194 185-192 (2011).

43 Chen, L. N., Kuo, C. C., Chiu, Y. C. \& Chen, W. C. Ultra metal ions and pH sensing characteristics of thermoresponsive luminescent electrospun nanofibers prepared from poly(HPBO-co-NIPAAm-co-SA). RSC Adv. 4, 45345-45353 (2014).

44 Chen, B. Y., Huang, Y. S., Lu, S. T., Liang, F. C., Jiang, D. H. \& Kuo, C. C. Novel highly selective and reversible chemosensors based on dual-ratiometric fluorescent electrospun nanofibers with $\mathrm{pH}$ - and $\mathrm{Fe}^{3+}-$ modulated multicolor fluorescence emission. ACS Appl. Mater. Interfaces 7, 2797-2808 (2015).

45 Syu, J. H., Cheng, Y. K., Hong, W. Y., Wang, H. P., Lin, Y. C., Meng, H. F., Zan, H. W., Horng, S. F., Chang, G. F., Hung, C. H., Chiu, Y. C., Chen, W. C., Tsai, M. J. \& Cheng, $\mathrm{H}$. Electrospun fibers as a solid-state real-time zinc ion sensor with high sensitivity and cell medium compatibility. Adv. Funct. Mater. 23, 1566-1574 (2013).

46 Schwab, P. F. H., Fleischer, F. \& Michl, J. Preparation of 5-brominated and 5,5'dibrominated 2,2'-bipyridines and 2,2'-bipyrimidines. J. Org. Chem. 67, 443-449 (2002).

47 Chuang, W. J. \& Chiu, W. Y. Thermo-responsive nanofibers prepared from poly $(N$ isopropylacrylamide-co- $N$-methylol acrylamide). Polymer 53, 2829-2838 (2012).

48 Megelski, S., Stephens, J. S., Chase, D. B. \& Rabolt, J. F. Micro- and nanostructured surface morphology on electrospun polymer fibers. Macromolecules $\mathbf{3 5}$, 8456-8466 (2002).

49 Krishnan, S., Klein, A., El-Aasser, M. S. \& Sudol, E. D. Influence of chain transfer agent on the cross-linking of poly ( $n$-butylmethacrylate-co- $N$-methylol acrylamide) latex particles and films. Macromolecules 36, 3511-3518 (2003).

50 Frisch, M. J., Trucks, G. W., Schlegel, H. B., Scuseria, G. E., Robb, M. A., Cheeseman, J. R., Scalmani, G., Barone, V., Mennucci, B., Petersson, G. A., Nakatsuji, H., Caricato, M., Li, X., Hratchian, H. P., Izmaylov, A. F., Bloino, J., Zheng, G., Sonnenberg, J. L., Hada, M., Ehara, M., Toyota, K., Fukuda, R., Hasegawa, J., Ishida, M., Nakajima, T., Honda, Y., Kitao, O., Nakai, H., Vreven, T., Montgomery, J. A. Jr., Peralta, J. E., Ogliaro, F., Bearpark, M., Heyd, J. J., Brothers, E., Kudin, K. N., Staroverov, V. N., Keith, T., Kobayashi, R., Normand, J., Raghavachari, K., Rendell, A., Burant, J. C., Iyengar, S. S., Tomasi, J., Cossi, M., Rega, N., Millam, J. M., Klene, M., Knox, J. E., Cross, J. B., Bakken, V., Adamo, C., Jaramillo, J., Gomperts, R., Stratmann, R. E., Yazyev, O., Austin, A. J., Cammi, R., Pomelli, C., Ochterski, J. W., Martin, R. L., Morokuma, K., Zakrzewski, V. G., Voth, G. A., Salvador, P., Dannenberg, J. J., Dapprich, S., Daniels, A. D., Farkas, O., Foresman, J. B., Ortiz, J. V., Cioslowski, J. \& Fox, D. J. Gaussian 09, Revision B.01 (Gaussian, Wallingford, CT, 2010).

Supplementary Information accompanies the paper on Polymer Journal website (http://www.nature.com/pj) 